Home Healthc Now. 2017 ; 35(10): 561-565. doi:10.1097/NHH.0000000000000621.

\title{
Teaching Home-Based Primary Care
}

\author{
Jennifer M. Reckrey, MD, \\ Assistant Professor, Department of Geriatrics and Palliative Medicine; Assistant Professor, \\ Department of Medicine Division of General Internal Medicine, Icahn School of Medicine at Mount \\ Sinai, New York, NY \\ Katherine A. Ornstein, PhD, \\ Assistant Professor, Department of Geriatrics and Palliative Medicine; Assistant Professor, \\ Institute for Translational Epidemiology, Icahn School of Medicine at Mount Sinai, New York, NY
}

\author{
Ania Wajnberg, MD, \\ Associate Professor, Department of Medicine Division of General Internal Medicine, Icahn School \\ of Medicine at Mount Sinai, New York, NY
}

Victoria Kopke, MD, and

Assistant Professor, Department of Medicine Division of General Internal Medicine, Icahn School of Medicine at Mount Sinai, New York, NY

\section{Linda V. DeCherrie, MD}

Associate Professor, Department of Geriatrics and Palliative Medicine; Associate Professor, Department of Medicine Division of General Internal Medicine, Icahn School of Medicine at Mount Sinai,, New York, NY

\section{Abstract}

Despite the growing homebound population and the development of innovative models of care that work to bring care to people in their homes, home visits are not a routine part of education for many healthcare providers. This manuscript describes the experience of Mount Sinai Visiting Doctors in teaching home-based primary care to learners of various disciplines and reports the results of a survey performed to assess trainee experience. Mount Sinai Visiting Doctors is the largest academic home-based primary care program in the country and trainees of various disciplines have nearly 1700 contact days annually of directly supervised clinical teaching. In order to improve trainee education and meet our practice needs, trainees: 1) independently conduct urgent visits, 2) carry longitudinal panels of homebound patients, and 3) perform subspecialist consultations. Mount Sinai Visiting Doctors has exposed thousands of trainees to home-based primary care in the past 20 years and trainees report positive reviews of their experiences. As the need to train future providers in home-based primary care grows, we will be challenged to provide trainees with adequate exposure to multidisciplinary teams and to teach about the importance of continuity of care.

Corresponding author: Jennifer M. Reckrey, MD, One Gustave L Levy Place Box 1216, New York, NY 10029, Tel: 212-604-6534, Fax: 212-604-6590, Jennifer.reckrey@ mountsinai.org.

The authors declare no conflicts of interest: 


\section{Background}

Estimates indicate at least 2 million individuals are permanently homebound and millions more are temporarily homebound (Ornstein et al, 2015). Given the aging population's widespread preference to remain at home, the coming decades will see the number of permanently homebound individuals rise (Gillsjo, Schwartz-Barcott, \& von Post, 2011). Likewise, shorter hospital lengths of stay and an increased focus on treating acute conditions in the community will increase the number of temporarily homebound individuals (Shepperd et al., 2016). The homebound often have difficulty accessing medical care, and home-based primary care is an effective way to provide high quality, lower-cost care (De Jonge et al., 2014; Leff et al., 2015). In addition to home-based primary care, a growing number of innovative care delivery models provide care at home including home-based palliative care, hospital at home programs, and home visits as patients transition home from the hospital (Shepperd et al., 2016; Ventura et al., 2014).

The American Academy of Home Care Medicine has developed clinical competencies for clinicians caring for patients in their homes and competencies in home care are a part of both family medicine and internal medicine training (Hayashi \& Christmas, 2009). Yet despite its importance, medical education and training in home visits is often lacking. Survey data from 2001 suggested only $25 \%$ of internal medicine residents obtained any home visit experience during their training (Stoltz, Smith, \& Boal, 2001). This may leave the majority of healthcare providers inadequately prepared to care for the growing homebound population and unable to knowledgeably participate in or collaborate with programs that provide care at home.

\section{Context}

Described elsewhere in detail, the multidisciplinary Mount Sinai Visiting Doctors (MSVD) program provides medical and psychosocial support to help homebound patients improve their quality of life and symptom control and maximize their health and independence (Ornstein et al., 2011). Adult patients of all ages are referred to MSVD from a variety of hospital and community-based sources for conditions such as dementia, frailty, psychiatric illness, and gait impairment. The physicians, nurse practitioners, registered nurses, social workers, and administrative assistants work in teams to make more than 7,500 home visits each year throughout Manhattan.

Trainees including medical students, medical residents, geriatric and palliative care fellows, social work interns, nurse practitioner students, subspecialist trainees, and others are a key part of the MSVD program. No patient can opt out of having trainees participate in their care. On any given day, several trainees participate in new patient, follow-up, and urgent visits. Depending on their discipline and level of training, they rotate through the program for a varying number of days (see Table 1). Currently, the MSVD program provides nearly 1700 contact days annually of directly supervised clinical teaching.

Safety is an important concern for all our staff and trainees during home visits and we have developed key safety recommendations that we address with all new staff and trainees either 
via email or in person prior to caring for patients at MSVD (Table 2). Trainees never make visits alone; they are always in pairs or accompanied by an attending or supervisor. No MSVD staff or trainee has ever had a major safety incident.

\section{Innovations in Education}

All trainees at MVSD spend at least one day working directly with an attending physician or a senior-level supervisor in their field. Many providers take advantage of this opportunity to discuss social determinants of health and how to incorporate patients' goals of care into decisions for a medically complex older population, two lessons that MSVD and other home-based primary care programs are uniquely able to teach trainees. In addition, teaching during home visits themselves is often supplemented by a variety of classroom-based lectures about home care incorporated into the existing didactic schedules for trainees' respective programs. In order to improve the overall training experience while accommodating a growing number of trainees, MSVD has implemented various innovative teaching strategies which increase educational opportunities while also helping the program meeting patients' clinical needs.

Urgent visits by trainees-Experienced resident physicians and fellows are accompanied by a medical student or other trainee as they visit an established patient in the program who has an acute complaint. Prior to the visit a faculty preceptor reviews all MSVD urgent visit requests and makes sure each trainee-led team has the appropriate background and understanding of the urgent complaint. Teams see patients on their own and call the preceptor with problems or questions. Treatment plans are developed as a team, following an in-person debriefing with the faculty preceptor.

Longitudinal follow-up of patients-Select trainees are assigned two to four patients to follow independently over the one to two years of their respective program. All trainees are the primary provider responsible for their patients and see their patients during assigned patient care sessions throughout the year, and they work with an assigned faculty preceptor who is available to assist as needed. In addition to being supervised by a preceptor, trainees also work closely with the patient's MSVD multidisciplinary care team (e.g., social work, nursing.)

Subspecialist trainee consultations-MSVD has partnered with a number of residency and fellowship programs within our academic medical center to arrange for specialist trainees to make home visits. Currently MSVD providers can place referrals for home visits by rheumatology, neurology, and psychiatry. Residents and fellows are paired with another trainee to do home-visit consults. They then precept with a faculty member from within their discipline, develop a treatment plan, and give recommendations for care to MSVD providers. While most subspecialist trainee consults are for one home visit only, if needed the subspecialist trainees can return to see homebound patients for follow-up.

\section{Trainee Experience}

At the end of a training period, all medical trainees (medical students, residents, and fellow) complete a brief, anonymous paper survey. The survey uses a 5-point Likert scale to assess 
trainee attitudes towards home care, perception of safety during visits, and satisfaction with role during visits. It was developed by MSVD physician educators to learn about the trainee experience at MSVD and is based on reviews of the existing literature that described medical student attitudes towards home care (Flaherty et al., 2002). The survey responses collected over four academic years (2008-2012) were entered into an Excel file by a research assistant and descriptive statistics were calculated using SAS v. 9.2.

A total of 370 out of 744 medical students, residents, and fellow medical trainees completed the evaluation, which represents a 50\% response rate. Primary care residents and first year geriatrics and palliative medicine fellows did not rotate at MSVD during these years. Respondents were 304 medical students, 56 residents, and 10 fellows. Among all trainees, the vast majority (96\%) felt that caring for the homebound was valuable; that the rotation increased their awareness of the importance of caring for older adults (90\%); and that caring for the underserved was important (85\%). Fifty-nine percent of trainees felt "always safe" (defined as a 4 or 5 on a 5 point Likert scale). Only 5\% reported that they mostly did not feel safe (defined as 1 or 2 on a 5 point Likert scale) (Table 3.) The majority of residents (88\%) and fellows $(80 \%)$ felt that the time in an observational vs clinical role was "about right". The majority of residents (83\%) and fellows (80\%) also felt they had the opportunity to teach students.

\section{Implications}

MSVD's over 20-year experience providing successful training experiences for trainees of multiple disciplines at various levels provides many lessons to others seeking to incorporate home visits into their programs. The innovative approaches to trainee education described above are important because they not only improve training experience, but also help meet concrete needs of the MSVD practice. Trainee-conducted urgent visits minimize disruption attending providers' scheduled follow-up visits and longitudinal follow-up by trainees increases the number of patients MSVD can care for thereby decreasing waitlist times. Also, subspecialist trainee consultations bring medical specialist care to patients who are unable to leave home to access care in an outpatient setting.

It is important to note that over the years, MSVD has had to be flexible and significantly alter our trainee experiences due to changes in training program curricula. For example, medical students' schedules change year-to-year, so we incorporate them in home visits for anywhere from two to five days each, depending on the availability in their curriculum. Given many trainees often have only a short time at MSVD, teaching the importance of continuity of care remains an ongoing challenge. We are also working to expose trainees to the value of multidisciplinary care, yet time constraints and discipline- specific requirements often make it difficult to provide trainees with direct cross-disciplinary learning opportunities. As we educate the next generation of providers in home-based primary care, we are actively looking for ways to better integrate trainees of various disciplines in a true interprofessional education model.

As innovative clinical programs work to meet the needs of the increasing number of homebound individuals and new models of care bring services directly to people in their 
homes, home-based care will become more and more common. Trainees at all levels and of all disciplines need exposure to home-based primary care. The experiences of MSVD, the largest academic home-based primary care program in the country, should inform other educators seeking innovative ways to provide training in care at home.

\section{References}

De Jonge KE, Jamshed N, Gilden D, Kubisiak J, Bruce SR, Taler G. Effects of home-based primary care on Medicare costs in high-risk elders. Journal of the American Geriatric Society. 2014; 62(10): 1825-1831.

Flaherty JH, Fabacher DA, Miller R, Fox A, Boal J. The determinants of attitudinal change among medical students participating in home care training: a multi-center study. Academic Medicine : Journal of the Association of American Medical Colleges. 2002; 77(4):336-343. [PubMed: 11953303]

Gillsjo C, Schwartz-Barcott D, von Post I. Home: the place the older adult cannot imagine living without. BMC Geriatrics. 2011; 11(10)

Hayashi J, Christmas C. House calls and the ACGME competencies. Teaching and Learning in Medicine. 2009; 21(2):140-147. [PubMed: 19330693]

Leff B, Weston CM, Garrigues S, Patel K, Ritchie C. National Home-Based Primary C, et al. Homebased primary care practices in the United States: current state and quality improvement approaches. Journal of the American Geriatric Society. 2015; 63(5):963-969.

Ornstein K, Hernandez CR, DeCherrie LV, Soriano TA. The Mount Sinai (New York) Visiting Doctors Program: meeting the needs of the urban homebound population. Care Management Journal: Journal of Case Management. 2011; 12(4):159-163. [PubMed: 23214235]

Ornstein KA, Leff B, Covinsky KE, Ritchie CS, Federman AD, Roberts L, Szanton SL. Epidemiology of the homebound population in the United States. JAMA internal medicine. 2015; 175(7):11801186. [PubMed: 26010119]

Shepperd S, Doll H, Angus RM, Clarke MJ, Iliffe S, Kalra L, Wilson AD. Admission avoidance hospital at home. 2008

Stoltz CM, Smith LG, Boal JH. Home care training in internal medicine residencies: a national survey. Academic Medicine : Journal of the Association of American Medical Colleges. 2001; 76(2):181-3. [PubMed: 11158842]

Ventura AD, Burney S, Brooker J, Fletcher J, Ricciardelli L. Home-based palliative care: a systematic literature review of the self-reported unmet needs of patients and carers. Palliative Medicine. 2014; 28(5):391-402. [PubMed: 24292156] 


\section{Suggested callouts}

In addition, teaching during home visits themselves is often supplemented by a variety of classroom-based lectures about home care incorporated into the existing didactic schedules for trainees' respective programs.

Trainees at all levels and of all disciplines need exposure to home-based primary care. 
Table 1

Current instruction provided by Mount Sinai visiting providers

\begin{tabular}{|c|c|c|c|c|}
\hline Trainee & Training provided & Contact days */trainee & Number of trainees/year & Total contact days $/$ year \\
\hline $3^{\text {rd }}$ year medical students & $\begin{array}{l}\text { Ambulatory care with } \\
\text { a focus on geriatric } \\
\text { medicine }\end{array}$ & 2 & 125 & 250 \\
\hline $\begin{array}{l}2^{\text {nd }} \text { year internal medicine } \\
\text { residents }\end{array}$ & HBPC & 10 & 55 & 550 \\
\hline Primary care residents & Longitudinal HBPC & 12 & 2 & 24 \\
\hline $\begin{array}{l}1^{\text {st }} \text { year geriatric and palliative } \\
\text { care fellows }\end{array}$ & HBPC & 16 & 17 & 272 \\
\hline $\begin{array}{l}\text { 2nd year geriatric fellows and } \\
\text { palliative care fellows }\end{array}$ & Longitudinal HBPC & 12 & 6 & 72 \\
\hline Elective trainees & HBPC & 20 & 13 & 260 \\
\hline $\begin{array}{l}\text { 3rd year students accepted } \\
\text { early to med school }\end{array}$ & $\begin{array}{l}\text { Introduction to clinical } \\
\text { medicine }\end{array}$ & 1 & 24 & 24 \\
\hline Nurse practitioner trainees & HBPC & 20 & 10 & 200 \\
\hline Social work interns & HBPC & 50 & 2 & 100 \\
\hline Specialty trainees & Home-based consults & 4 & 10 & 40 \\
\hline Totals & & 246 & 264 & 1692 \\
\hline
\end{tabular}

* A contact day refers to any calendar day for which a trainee receives any instruction from the program's providers 


\section{Table 2}

\section{Safety Recommendations}

\begin{tabular}{|l|l|}
\hline 1 & Always be aware of your surroundings. \\
\hline 2 & Do not use stairs behind closed doors. \\
\hline 3 & Always have a cell phone. \\
\hline 4 & Ask pets to be locked in a separate room before you enter the apartment. \\
\hline 5 & Leave immediately if you feel unsafe for any reason. \\
\hline 6 & Call your preceptor immediately with any safety concerns. \\
\hline
\end{tabular}




\section{Table 3}

Responses of End of the Rotation Survey for All Trainees for 5 years (2008-2012), n=370

\begin{tabular}{|l|c|}
\hline Question & Agree or strongly agree \\
\hline Felt always safe during visits & $59 \%$ \\
\hline Felt never safe during visits & $5 \%$ \\
\hline Caring for the homebound is valuable & $96 \%$ \\
\hline The rotation increased my awareness that learning to care for the elderly is an important part of my education & $90 \%$ \\
\hline The rotation increased my awareness that learning to care for the underserved is an important part of my education & $85 \%$ \\
\hline
\end{tabular}

